\title{
1 Energy efficient climate control in office buildings without giving up implementability
}

2 Mattias Gruber $^{\mathrm{a}, \mathrm{b}^{*},}$ Anders Trüschel ${ }^{\mathrm{b}}$ and Jan-Olof Dalenbäck ${ }^{\mathrm{b}}$

3 a ESBE AB, Bruksgatan 22, 33021, Reftele, Sweden.

E-mail address: mattias.gruber@esbe.eu

\section{$7 \quad$ Nomenclature}

8

9

20

\section{Abstract}

The adaptation between a building and its automation system can potentially be increased by model-based
$\mathrm{CO}_{2}$ concentration [ppm] specific heat capacity $[\mathrm{J} /(\mathrm{kg} \mathrm{K})]$ thermal power [W] celsius temperature $\left[{ }^{\circ} \mathrm{C}\right]$ controller input of thermal disturbances [W] volume flow rate $\left[\mathrm{m}^{3} / \mathrm{s}\right]$ controller output in ventilation flow quantities $\left[\mathrm{m}^{3} / \mathrm{s}\right]$

Greek letters

$\rho \quad$ density $\left[\mathrm{kg} / \mathrm{m}^{3}\right]$

Subscripts

act activation

adj adjacent

s supply

sp setpoint

r room controllers with an integrated control model and information about indoor climate disturbances. The associated energy savings potential is large but a widespread utilization is typically prevented by high complexities. From that point of view, a trade-off technology that combines implementability with an overall higher performance than the system of current practice would be a better option at most sites. This work presents an experimental evaluation of an alternative controller that follows the same principle as model-based, but has gone through a large number of simplification measures for a reduced overall complexity and a limited function. The controller was evaluated for indoor climate control by automating the ventilation flow rate during a typical office working 
day that was re-created in a laboratory environment. Experiments were conducted in two different office sites, as well as during two weather seasons of Swedish summer and winter. From the investigation, it was concluded that despite of the reduced complexity, the investigated controller could save between $12-19 \%$ of indicated energy compared to a system of common practice at the same time as the quality of indoor climate was maintained.

\section{Keywords}

Office buildings; Indoor climate control; Implementability; Air-based heating and cooling; Energy efficiency; Model-based controller

\section{Introduction}

A way of achieving cost- and energy efficient retrofits in buildings is to improve the building automation system (BAS). A high energy savings potential follows from that the BAS manages the operation of the HVAC (heating, ventilation and air-conditioning) system which in turn stands for approximately $76 \%$ of the total energy usage in European buildings [1]. At the same time, implementation of new BAS technologies is to a certain degree possible without major system changes, which means that installation costs can be small compared to the revenues.

As the BAS acts as an interface between the building and the HVAC system, the HVAC operation can be improved by increasing the adaptation to prevailing conditions by incorporating relevant information about building characteristics, the activities inside the building, the ambient climate etc. In this way, the necessary actions for achieving a desirable indoor climate from a static and dynamical point of view can be estimated before any deviations from desirable comfort regions occur. Also, the control activity could be planned ahead by anticipating future demands which opens up for the possibility of reducing energy usage by deciding on the most preferable actions. In its broadest sense, this technology is referred to as model-based control. A typical configuration includes a sensing system that gathers information about indoor climate disturbances as exogenous inputs to an integrated control model. The control model is used to predict the corresponding impact on the controlled variables, and to adjust the HVAC control signals to achieve a desired behavior of the process, based on some given criterion.

Several previous works have indicated that model-based controllers can result in energy savings from about 20 to $50 \%$ without compromising comfort [2-6]. However, a typically high level of complexity means that implementation at most common sites are prevented along with a widespread utilization. Important aspects in 
this context are the number of disturbances considered as exogenous inputs, their quantifiability, how the associated information is processed by the control model as well as how input errors and deficiencies are compensated for. A complete correspondence between process and control model as well as information about all relevant indoor climate disturbances would potentially lead to a perfect adaptation between BAS and building. But, such controller is also associated to high installation costs, comprehensive commissioning as well as continuous maintenance to update for changes in the process. For that reason, extensive controller designs are unrealistic for considering in the majority of buildings.

Most previous works within the field of simplified model-based controllers have focused on finding control models that require less manual work than physical system representations, but still has the ability to predict the behavior of the indoor climate sufficiently accurate for a sufficient time ahead [7-12]. In [7], historical data from an office building was used to define a control model for predicting the indoor climate quality using HVAC power usage and weather as inputs. The model was furthermore validated by assessing the perceived indoor climate in the building and it was shown that the model-based controller could achieve energy savings between 19 and $32 \%$ compared to a baseline. In [8], a model-based controller with real-time flight schedules and electricity prices as inputs was investigated for temperature control in an airport. The considered control model was of grey-box type where a linearized physical representation was used as a starting point and an identification algorithm was applied together with historical data to capture nonlinearities and physical parameters through a process described in [9]. It was shown that the performance of the adapted control model was accurate enough to save $41 \%$ of the energy compared to a baseline control approach. Also [10] focused on a grey-box control model for predicting zone temperatures in an office building using fore-cast of outdoor air temperature, solar radiation, occupancy and internal heat gains as inputs. It was shown that the model could return accurate predictions over a horizon of two days and that the associated model-based controller led to energy savings of 17 $\%$ compared to a conventional control system.

There are also some examples in literature on reducing the complexity associated to gathering and processing disturbances before used as exogenous inputs to the control model. Goyal [13] and Oldewurtel [14] et al. compared the benefits of utilizing future or present occupancy information as retrieved from prognosis or measurements, respectively, as inputs to model-based controllers for indoor climate control in office sites. The complexity aspect comes from that accurate forecasts typically require comprehensive models that are based on an extensive set of historical data while measurements can be generated in a more straight forward way. The results from the studies were consistent and showed that measurements were sufficient for achieving energy 
savings around $50 \%$ in comparison to conventional controllers, while only small additional gains were provided through prognosis. Forecasts of indoor climate disturbances for control applications were also considered in [15] and [16], but with the focus on models for improving predictions. While [15] considered a self-tuning occupancy prediction model, [16] aimed to account for uncertainties in the control, and both investigations showed that their algorithms were beneficial.

Even though the cited works have showed that it is possible to reduce the complexity of model-based controllers without compromising performance, there are three reasons to why the proposed simplification measures cannot be considered as sufficient in typical building automation applications. First, complexity regarding control model and exogenous inputs were addressed individually which means that an overall low complexity could not be guaranteed. Second, complexity associated to gathering exogenous inputs were only investigated for a few examples (typically occupancy) and not for the entire set. Third, control or disturbance prediction models based on black- or grey-box algorithms might still be too complex since a large amount of training data is required in order to avoid a highly limited validity range [17]. In order to achieve a large scale implementation of modelbased controller for indoor climate control, an overall low complexity is required. In turn, most simplification measures will have a negative impact on control performance. But in typical sites, a compromise between simplicity and performance is presumably sufficient, as long as a sufficiently high implementability can be combined with a considerable higher control performance than BASs of current practice.

\subsection{Purpose and procedure}

This paper contributes in the search for simple and energy efficient BAS by providing an experimental evaluation of an alternative controller that follows the same principle as a model-based but has gone through a large number of complexity reducing measures. This process was described in a previous publication [18] where the starting point was a controller with a complete energy balance of an office site and perfect information about all thermal disturbances in real-time. By predicting the influence of any changed condition, a perfect response in both time and magnitude for maintaining a desirable indoor climate could be achieved using as little energy as possible. In the next step, a number of proposed simplifications were step-wise applied on the control model or on the exogenous inputs, while their cumulative effect on control performance consistently was evaluated and restrained through simulations. Several alternative control models were evaluated and a systematic search for the disturbances with the largest potential as exogenous inputs was conducted. An overall low complexity and a maintained control performance was achieved by limiting the exogenous inputs to the most common internal 
disturbances as well as by replacing the energy balance with a closed-loop non-linear filter. The function of the controller was thereby limited to achieving a desirable indoor climate using as little energy as possible by anticipating the short-term and current effects of the considered disturbances. Therefore, the controller will from now on be referred to as a simplified anticipating controller (SAC).

As will be properly described in section 3.3, the SAC is used to process exogenous inputs consisting of measured internal disturbance to achieve a close to lag-free compensation on the room air temperature in office sites. The exogenous inputs are scaled by the non-linear filter in a closed-loop fashion to achieve responses that are adapted to the current and the desired indoor climates. Since only internal disturbances are taken into account by the nonlinear filter, compensation of remaining thermal disturbances is managed through a parallel feed-back function. In total, the SAC requires only one additional parameter compared to a normal feed-back which facilitates implementation considerable compared to conventional model-based controllers.

This paper belongs to a larger research project in which a similar methodology was applied for evaluating different HVAC system variants in office environments with respect to automation possibilities of the SAC. Previous publications have considered hydronic heating/cooling via a fan-coil unit as well as fresh air supply via a mechanical VAV (Variable Air Volume) ventilation system [19]. These two subsystems were mainly differentiated by their dynamical properties, and it was shown that the SAC was most beneficial for automating the ventilation part due longer transport delays in system and process. For that reason, the present paper focuses on an all-air HVAC system for heating, cooling and supplying fresh air via mechanical ventilation.

Experiments were conducted during a typical working day that was re-created in a test facility by imitating internal disturbances in sequences. The task of the SAC was to maintain the IAQ (Indoor Air Quality) and thermal climate indicated by measured $\mathrm{CO}_{2}$ and temperature, respectively, through integrated room automation of ventilation flow rate. Experiments were conducted in two separate spaces representing a meeting and an office room with respect to working activity, layout and size. Furthermore, two weather seasons of Swedish summer and winter were considered, and each scenario was repeated, first with the SAC, and then with a conventional feed-back controller as a benchmark for current practice. As an experiment stretched over a working day, the investigation focused on circumstances when a desirable indoor climate is of utmost importance for avoiding discomfort and productivity losses. Further, a typical consequence during such periods is high HVAC energy usages; partly due to high loads, and partly since the room for energy reducing measures such as setpoint resets or free-cooling etc. is small. These two features were 
emphasized in the comparison between SAC and benchmark, by constraining the controllers to achieve equally desirable indoor climates while the associated HVAC energies were used as a performance metrics.

\section{Investigation}

149 The investigation was conducted during one calendar year in a $300 \mathrm{~m}^{2}$ large university test facility located in Gothenburg, Sweden. The facility (fig. 1 ) is commonly used for research and education within the field of building services engineering, and contains multiple sites and various equipment for studying different areas involved in the subject. An experimental HVAC system stretches throughout the building whereof most parts were involved to some extent in this work at the same time as the actual experiments took place in the seminar room located at the entrance floor in the north-west corner (fig.2). To facilitate for the reader, the site and the associated systems are in the following text divided into three levels, based on their purposes during the investigation. Further on, this description is followed by presentations of the re-created working day and the associated experimental design.

\subsection{Experimental framework}

The seminar room in figure 2 has a floor area of $5.6 \times 6.2 \mathrm{~m}$ and a height of $2.4 \mathrm{~m}$. The envelope is of gypsy and mineral wool while the framing is of concrete and steel. The walls represented as left and top in the figure are external, whereof the left has a section of outside solar shaded windows over most of its length. The remaining walls as well as the ceiling are adjacent to other parts of the building, while the floor is made up of a ground connected concrete slab. Indoor climate control with respect to heating, cooling and air renewal is provided by a VAV mechanical ventilation system. In table 1 , the parts of the HVAC system involved in the investigation are presented together with an overview of their purposes and how they were controlled during the experiments.

The first level in table 1 is made up of an open hall in which a number of units for production and storage of hot and cold water are installed. During the experiments, a dry-cooler together with a combined heat pump/chiller (simultaneous production of hot and cold water) managed the base supply while an electrical boiler functioned as auxiliary system. During the experiments, sequence control was applied to maintain constant temperature setpoints in a number of tanks from which heating and cooling carriers in turn were distributed through a piping system. The second level is made up of an air-handling unit (AHU) in which two speed-controlled fans were used to ventilate the seminar room (third level) via four ducts each for supply and exhaust air. On the supply-side of the AHU, OA (Outdoor Air) was conditioned over two finned water-connected air coils with the carriers as 
heating and cooling media respectively. The air temperature and humidity were controlled by varying the inlet

175 temperature on the water-side with an automated 3-way valve for mixing of the primary supply and the coil return as exemplified for the cooling circuit in figure 3. On the third level, the ventilation air was supplied and extracted through mixing roof-mounted diffusers in the seminar room. During the experiments, the investigated controllers were evaluated for integrated room automation of supply air flow rate by varying the opening of the associated diffuser. The same control signal was furthermore used on the second level to adjust the speed of the supply air fan, and at the same time, the exhaust system was controlled to follow the supply side to achieve balanced ventilation.

Remark: In this work, the supply-side of the ventilation system was entirely made up of conditioned OA while the exhaust air was discharged to the ambience. This principle is in accordance to Swedish common practice and is referred to as heat recovery ventilation (HRV) which is characterized by that heat is recovered from the exhaust to the supply by the means of a heat exchanger instead of recirculation of exhaust air [20].

\subsection{Experimental design}

Due to the symmetrical distribution of supply and exhaust air diffusers as illustrated in figure 2, the seminar room can be divided into separate modules. In this work, two variants (fig.4.) were considered on separate occasions by enclosing floor areas of 10 or $18 \mathrm{~m}^{2}$ with temporary walls (marked as filled) of glued sheets of thick Styrofoam. The sizes and layouts corresponded to an office (left) respective a meeting room (right) and ventilation was in both cases managed by a single pair of diffusers (marked out in fig.4). Each module could be accessed through a built-in door, and was assembled to represent spaces in modern office buildings, with tight and well-insulated envelopes.

\subsubsection{Re-created working day}

During the experiments, typical working days of meeting or office room activities were re-created in the associated space by imitating the following internal disturbance in 9 hour sequences.

- Occupancy (referring to the number of people)

$$
\text { - Lighting }
$$

- Equipment 
201 Occupancy was re-created as the sequences in figure 5 that were constructed using annual statistical data from a 20258 room large Swedish office building [21]. By comparing these sequences to recommendations regarding the 203 design number of occupants for the associated space and activity [22], the office room was fully occupied except during lunch time (11:30 -13:00), while the maximum occupancy factor in the meeting room reached about 70 $\%$. The occupants were in turn imitated by burning candles of a type that was confirmed to have a close correspondence to the heat and $\mathrm{CO}_{2}$ emitted by an office worker as presented in figure 6 . These results were produced by measuring and comparing temperature and $\mathrm{CO}_{2}$ responses in a confined space with either one person performing office activities or one burning candle. Further, lighting and equipment were assumed to be dependent on the occupancy sequences, and were imitated by modulating the heating power output of a whitepainted electrical panel radiator. According to the national standard SS-EN 12464-1 [23], a sufficient lighting corresponds to $10 \mathrm{~W}$ of heat per $\mathrm{m}^{2}$ of floor area which was re-created as $\mathrm{ON}$ during occupied periods and OFF during vacancy. The equipment part in the meeting room was consistently re-created with $50 \mathrm{~W} / \mathrm{imitated}$ person, while set to $100 \mathrm{~W}$ between the initiation and finalization of the occupancy sequence in the office room (to represent a computer that runs all day but is turned off outside office hours). Finally, the door was throughout closed in the meeting room scenario, while open for approximately one hour (14:30 -15:20) during the afternoon in the office room case.

\subsubsection{Internal vs. external disturbances}

In the meeting room space, the ambient influence on the indoor climate was minimized by providing sufficient air-gaps between temporary and external walls, as can be observed in figure 4 . In contrast, the associated internal disturbances were occasionally large since the respective occupancy sequence exclusively contained more than one person at the same time. In the office room case, the proportions were the opposite due to the external fenestrated wall in combination with a design-occupancy of one person. Hence, the two spaces represented its own extreme regarding the dominating origin of indoor climate disturbances, and this experimental layout was chosen to span the results from the investigation so that most relevant cases can be found within the range. Moreover, the design of the office room environment and diverse outdoor air temperature (OAT) during the considered time period enabled the investigation to span over scenarios when the HVAC system operated in heating as well as cooling mode by repeating these trials for cold (about $-10^{\circ} \mathrm{C}$ ) as well as warm $\left(\right.$ about $+20^{\circ} \mathrm{C}$ ) 
ambient climates. On the other hand, the governing conditions in the meeting room did not allow the same extension and these trials were throughout characterized by consistent cooling demands.

\subsubsection{Supply air temperature levels}

231

Throughout the study, constant supply air temperature levels of either 15 or $25^{\circ} \mathrm{C}$ were maintained during cooling and heating mode, respectively. This strategy was primary chosen to maintain generality by preventing the results from being influenced by any subjective elements in a supply air temperature algorithm. Furthermore, the comparability between trials repeated with the SAC and benchmark was also increased in this way. The levels were in turn chosen to achieve a high transparency by providing ideal prerequisites for the investigated controllers in each trial: the lower level is the minimum for avoiding draught [24] while the higher is the observed maximum for a maintained ability of providing the desired heat via ventilation without compromising IAQ. That is, the supply air temperature implied a minimum of required ventilation flow rate throughout the study, which means that less effort was put on the investigated controllers.

\subsection{Experimental setup}

In accordance to the common methodology that previously was applied in $[18,19]$, the test equipment was equivalently placed along a straight line between the active pair of air diffusers (see fig.4). In order to maximize the propagation of emitted heat and $\mathrm{CO}_{2}$, the burning candles and the radiator were placed in the middle on a $1 \mathrm{~m}$ high table and on the floor, respectively. The indoor climate was in turn indicated by measured room air $\mathrm{CO}_{2}$ and temperature using uncovered sensor-elements with accuracies of $\pm 50 \mathrm{ppm}$ and $\pm 0.1^{\circ} \mathrm{C}$, respectively. To avoid these measurements from being directly influenced by walls, the supply air stream or disturbances, the sensors were mounted in the free air on a tripod located at least $2 \mathrm{~m}$ from the disturbances on their exhaust air diffuser side [25]. The vertical positions were in turn selected using the BBR19 comfort zone, in which indoor climate constraints are valid and regions close to floor, ceiling and walls are excluded [22]. Since the considered weather seasons both implied heating and cooling modes, the temperature sensor was placed in the middle of this zone to avoid higher or lower temperatures than the average. The $\mathrm{CO}_{2}$ sensor was in turn placed on the upper boundary were the highest concentrations were expected.

\section{Controllers and control systems}

The SAC and the benchmark were separately evaluated for room air temperature control through flow rate automation of the VAV ventilation system, while the minimum allowed level was set to maintain a desirable 
$\mathrm{CO}_{2}$ level during the experiments. In this section, it is first presented how the controllers were evaluated for these tasks. Then, a detailed description of their structures and designs are provided.

258

259

\subsection{Evaluation method}

The controller comparison was performed according to the method in [18] which is based on the two most important HVAC system functions: indoor climate is to be kept within given comfort ranges, by preferably using as little energy as possible [26]. The indoor climate aspect was taken into account by considering current standards and guidelines to formulate two comfort criterions (one each for IAQ and thermal climate) that both controllers were constrained to fulfill within feasible limits. These are presented in the following text and were realized by first applying the SAC in a certain scenario. The same scenario was then repeated with the benchmark after applying appropriate setpoint adjustments for similar comfort as observed in the first case. In turn, the performances of the controllers were measured by the associated HVAC system energy usage and these coherent experiments were performed during two consecutive days in order to reduce the influence of weather variations. The maximum allowed difference of average OAT between these days was set to $2{ }^{\circ} \mathrm{C}$, and for larger variations, one of the experiments was repeated during more suitable conditions.

The IAQ was indicated by the room air $\mathrm{CO}_{2}$ concentration $\left(c_{r}\right)$ and the associated comfort constraint is presented in equation 1. It states that the level was not allowed to cross an absolute boundary of $1000 \mathrm{ppm}$, either when the SAC or the benchmark controller was implemented. This constraint is based on several national recommendations [27] as well as on the ASHRAE (American Society of Heating, Refrigeration and AirConditioning Engineers) standard 62-2007 [28].

$$
\hat{c}_{r, S A C}=\hat{c}_{r, \text { benchmark }}=1000 \quad[\mathrm{ppm}]
$$

The quality of the thermal climate was indicated relative to a room air temperature $\left(t_{r}\right)$ comfort region between 21 and $22{ }^{\circ} \mathrm{C}$. The first endpoint was set according to a national guideline [24] which states that lower temperatures should be avoided in occupied office rooms. The second endpoint was set $1 \mathrm{~K}$ higher, since according to the standard ISO 7730:2005 [29], smaller room air temperature variations do not have a negative effect on the thermal comfort, and similar recommendations are also given in ASHRAE standard 55-2004 [30]. The associated comfort constraint is presented in equation 2 and states that the deviating degree hours above and below this region should be similar when the SAC and the benchmark were applied. This metric derives from the 

vacancy without any penalties. It is worth pointing out that a more common metric in this context is the PMV during steady-state and is hence not suitable for the transient conditions studied in this work.

$$
\left\{\begin{array}{l}
\left(\left.\sum \Delta t_{\text {high }}\right|_{\infty, 0} \times \text { time }\right)_{S A C} \approx\left(\left.\sum \Delta t_{\text {high }}\right|_{\infty, 0} \times \text { time }\right)_{\text {Benchmark }} \\
\left(\left.\sum \Delta t_{\text {low }}\right|_{\infty, 0} \times \text { time }\right)_{S A C} \approx\left(\left.\sum \Delta t_{\text {low }}\right|_{\infty, 0} \times \text { time }\right)_{\text {Benchmark }}
\end{array}\right.
$$

Provided that the space is occupied

$$
\begin{aligned}
& \text { Where } \\
& \left\{\begin{array}{l}
\Delta t_{\text {high }}=t_{r}-22 \\
\Delta t_{\text {low }}=21-t_{r}
\end{array}\right.
\end{aligned}
$$

\subsection{Benchmark feed-back controller}

287 The benchmark feed-back (FB) lacked information about disturbances and solely relied on measured room air temperature as input. Its general structure is presented in figure 7 (top), and the control signals were generated by first forming a control error as the difference between input value and a fixed setpoint. This signal was in turn processed by proportional (P) and integrating (I) blocks and a final transformation from ventilation flow rate quantities to actuator compatible signals was performed by a second cascade connected controller. The PI-blocks were tuned using the AMIGO step response method. It is not the most common method but derives from a large number of optimization procedures and approximately returns the controller parameters that minimize the deviation from the setpoint [33].

\subsection{Simplified anticipating controller (SAC)}

The schematics of the investigated controller are presented in the bottom of figure 7: the exogenous input constitutes the total heat from the imitated internal disturbances and the control model is made up of a non-linear filter assisted by a feed-back controller. As mentioned, the overall principle was adopted from model-based controllers, but while reducing the complexities of both control model and inputs in the process. The function was thereby limited to anticipating the current and short-term effects of measured disturbances in order to achieve a desirable indoor climate using as little energy as possible. 
303 While model-based controllers in most previous publications had information about the entire set of disturbances, the exogenous inputs to the SAC is limited to the imitated sequences presented in section 2.2.1. That is, while information about heat emissions from occupancy, lighting and equipment were provided together with the heat exchange through an open door, all external disturbances such as OAT, solar radiation, infiltration as well as temperatures in adjacent rooms were managed indirectly by the parallel feed-back function.

To reduce the number of parameters influencing the result from the investigation, an ideal disturbance sensing system was assumed. That is, the imitated disturbance sequences were directly provided to the controller without any time-delays or errors. This is primary a simplification from an occupancy point of view due to the lack of established measurement methods for determining the number of people in a given space. But, as proposed in [34], $\mathrm{CO}_{2}$ sensors and simple algorithms can be used to return estimations that are accurate enough to maintain a high control performance in the concerned application.

The non-linear filter was designed to process exogenous inputs expressed in thermal power units, which was known for the imitated lighting and equipment through direct measurements. Also the heat emission from the imitated occupancy could be expressed by assuming $70 \mathrm{~W}$ per imitated person. However, in order to quantify the heat exchange through an open door in the office room scenarios, a two-step processing was first required. As the door was opened, the associated infiltration flow rate $\left(\dot{V}_{d o o r}\right)$ was first calculated using the empirical equation $3[35]$ including three predefined parameters: the height $(H[\mathrm{~m}])$ and the area $\left(A\left[\mathrm{~m}^{2}\right]\right)$ of the door as well as a constant $(K)$ which is dependent on the geometries of the controlled space and the adjacent (adj) room. $K$ was in this work determined experimentally but standard values given in [35] can also be used. Secondly, after the infiltration flow rate had been calculated, equation 4 was used to calculate the heat exchange to the room (

$$
\begin{array}{ll}
\dot{V}_{\text {door }}=K_{\text {door }} \cdot A_{\text {door }} \cdot\left(H_{\text {door }} \cdot\left|t_{\text {adj }}-t_{r}\right|\right)^{p .5} & {\left[\mathrm{~m}^{3} / \mathrm{s}\right]} \\
\dot{Q}_{\text {door }}=\dot{V}_{\text {door }} \cdot \rho_{\text {air }} \cdot c_{p, \text { air }} \cdot\left(t_{\text {adj }}-t_{r}\right) & {[\mathrm{W}]}
\end{array}
$$


A typical model-based controller utilizes a complete model of the process for predicting the short- and long-term influence of exogenous input. In order for physical models to be sufficient for this task, a large number of parameters would be required whereof several are uncertain or hard to determine. Another alternative are blackbox models that are constructed from observed data in terms of input/output measurements. But since the accuracy immediately becomes uncertain in ranges not covered by past data, the commissioning phase can be an extensive process. The control model of the SAC was instead reduced to a non-linear filter assisted by a feedback controller identical to the benchmark. The individual parts were designed to return supply quantities (i.e. ventilation flow rates) and the outputs were summed up and transformed into actuator compatible signals (by a cascade connected controller). As the assisting feed-back was used to compensate for errors (such as unmeasured or faulty measured disturbances) and thereby managed the base supply, the purpose of the non-linear filter was to act fast and accurate to changes in the exogenous inputs.

As the present room air temperature was used as input, the filter is characterized as of closed-loop type, and the associated output signal dependence is presented in figure 8 . The separate parts in equations $5 a$ and $5 b$ were used during cooling and heating modes respectively, through an IF-condition for automatic selection by comparing the supply and room air temperatures: that is, IF $t_{s}-t_{r}<0$, THEN $5 a$, ELSE $5 b$. The total heat emitted by the exogenous inputs (imitated disturbances, $u$ ) were in both cases used to generate control signal outputs in power units; either associated to an increased cooling supply (eq. $5 a, 0 \rightarrow u$ on the x-axis in fig 8 ) or to a decreased heating supply (eq. $5 b,-u \rightarrow 0$ on the $\mathrm{x}$-axis in fig 8). In turn, equation 6 transformed these signals into the corresponding ventilation flow rate by acquiring the current room- and supply air temperatures $\left(t_{s}\right)$. In accordance to figure 8 , the filter parts were featured to modulate their output $(y)$ by scaling the exogenous inputs $(u)$ with respect to the current room air temperature $\left(t_{r}\right)$. The scaling properties are in turn determined by a pair of parameters, including the comfort region boundaries $\left(t_{\text {low }}: 21{ }^{\circ} \mathrm{C}\right.$ and $\left.t_{\text {high }}: 22{ }^{\circ} \mathrm{C}\right)$, and associated activation temperatures $\left(t_{a c t}\right)$. The activation temperatures were assigned values inside the comfort region close to the coherent boundary so that each parameter-pair covered a certain temperature area. For room air temperatures inside any of these areas, the filter output consisted of the exogenous input scaled down between 1 and $99 \%$. For room air temperatures above the comfort region (presuming cooling mode), the entire registered heat emission was utilized as cooling supply, and for room air temperatures below, the filter output was zero (presuming heating mode). Between the two activation temperatures, the outcome is dependent on the current mode as illustrated in figure 8 . 


$$
\begin{aligned}
& y_{\text {coolingmode }}=\left(\left.\left(\frac{t_{r}-t_{\text {act }, \text { high }}}{t_{\text {act }, \text { high }}-t_{\text {high }}}\right)\right|_{0,1} \times u\right) \\
& y_{\text {heating mode }}=-\left(\left.\left(1-\frac{t_{\text {act }, \text { low }}-t_{r}}{t_{\text {act }, \text { low }}-t_{\text {low }}}\right)\right|_{0,1} \times u\right) \\
& \dot{V}_{\text {vent }}=\frac{y}{\rho_{\text {air }} \cdot c_{\text {p,air }} \cdot\left(t_{s}-t_{r}\right)}
\end{aligned}
$$

\section{Results}

Table 2 presents the scenarios for which the investigated controller and the benchmark were compared. The associated results in the following section are presented as the HVAC energy usages indicated by the ventilation rates measured with an accuracy of $\pm 2 \mathrm{l} / \mathrm{s}$. Since equal and constant supply air temperature setpoints were used during all coherent experiments, this indicator is directly proportional to the air-handling energy. At the same time, the results were prevented from being influenced by OAT dependent air-handling energy and by operational dependent efficiencies due to unequal controller setpoints (for fulfilling the comfort constraints).

Three actions were applied in this chapter to facilitate for the reader. First, only the room air temperature part of the control task is presented while continuous observations during the experiments ensured that also the IAQ constraint $\left(\mathrm{CO}_{2}\right.$ concentrations below $\left.1000 \mathrm{ppm}\right)$ was fulfilled. Second, the energy indicator for each scenario is presented graphically in cumulative distribution functions (CDF) (i.e. sorted values from low to high on an increasing $\mathrm{x}$-scale). In this way, the left parts of the cooling mode graphs (in fig. 10 and 12) are associated to vacant periods and the right to periods with extensive cooling loads. Consecutively, the vice versa applies for the heating mode graph in fig. 10 . As a third action, the supply air flow rate was presented relative to the maximum allowed level which, in each scenario, was set to provide the necessary thermal power for a maintained thermal comfort.

\subsection{Office room scenarios}

371 In figure 9 and 10 , the controlled room air temperatures as well as the supply air flow rate are presented for the

372 office room scenarios. During cooling mode, the largest strain on the thermal climate occurred at 08:00. Then, all internal disturbances were initiated at the same time and thereafter, the equipment part was active throughout the rest of the day which means that the event that occurred at 13:00 had less influence. The comfort constraint was 
fulfilled by reducing the setpoint of the benchmark with $0.5^{\circ} \mathrm{C}$, and the corresponding influence on energy usage was equivalent to about $5 \mathrm{l} / \mathrm{s}$ which is visualized as the offset during vacant periods in figure 10 .

377

In heating mode, the largest strain on the thermal climate was instead due to the opening of the door at 14:20, which was the only heat sink that occurred during an occupied period. The comfort constraint was in this mode fulfilled by increasing the setpoint of the benchmark with $0.2{ }^{\circ} \mathrm{C}$ which, according to figure 10 , had a negligible influence on the supply air flow (i.e. the ventilation rates during vacant periods coincide). An important remark to figure 9 is that the temperature drops below $21{ }^{\circ} \mathrm{C}$ occurred during vacant periods and had therefore no negative influencing on the thermal climate according to the comfort constraint.

\subsection{Meeting room scenario}

In figure 11 and 12 , the results from the meeting room scenario are presented. The largest strain on the thermal climate was associated to the largest heat gain at 13:00. Similar comfort was achieved by reducing the setpoint of the benchmark with $1{ }^{\circ} \mathrm{C}$ which was equivalent to a supply air flow rate of about $9 \mathrm{l} / \mathrm{s}$. Also in this case, the temperature drops below $21^{\circ} \mathrm{C}$ in figure 11 occurred during vacant periods and had therefore no negative influencing on the thermal climate according to the comfort constraint.

\section{Conclusions and discussion}

In summary, it can be concluded that the investigated controller has the ability of reducing the HVAC energy usage and improving the indoor climate considerably compared to the benchmark. But, it was also shown that these benefits were somewhat dependent on the considered conditions. In general, the potential of the investigated controller increases with the extensiveness of the exogenous inputs, and was slightly larger during cooling modes than during heating modes.

\subsection{Improvements of comfort and energy efficiency}

In comparison to the benchmark, the room air temperature variations inside the space were extensively decreased when the SAC was implemented during cooling mode (especially in the meeting room case) but insignificantly during the heating mode. On the other hand, as presented in table 3 , considerable energy savings were indicated for all scenarios: the total amount of air that was supplied through ventilation over the re-created working day was decreased between 12 and $14 \%$ during the office room scenarios and with $19 \%$ during the meeting room scenario. By considering that ventilation systems typically are energy intense, both when it comes to electricity 
for fans as well as heating and cooling energy for air-handling, these reductions accounts for a large share of the total energy usage of the HVAC system.

\subsection{Sources of energy savings}

The indicated energy savings in table 3 can be explained by two features of the SAC which furthermore can be visualized in figures 10 and 12 . First, the main part is due to a fast response when a reduction of exogenous inputs was registered. Then, the output of the control model directly went from the initial state to a relatively accurate terminal state while the benchmark modulated between all intermediate states with an increased energy usage as consequence. This is visualized as the step-shaped and smooth curves in the CDFs associated to the SAC and the benchmark respectively. The second part of the energy savings derive from a fast response when an increase of exogenous inputs was registered. The main benefit of this feature was an increased comfort since the deviation from the associated region was limited. But, energy was also saved because the setpoint of the benchmark was adjusted for similar comfort, and this part stands for the entire savings potential during static conditions (vacancy and long-lasting occupied periods).

\subsection{The influence of comfort constraints}

Even though the comfort constraints were based on current indoor climate standards and guidelines, their role in this study can be argued. The purpose was to provide a comparison of the controllers on equal grounds, i.e. what energy usage can be expected if the primary function of a desirable indoor climate already has been fulfilled. But in real life situations, such comparison is somewhat insufficient since a baseline of a desirable indoor climate cannot be guaranteed. Hence, even if it is obvious that the indoor climate can be improved if a conventional feed-back controller is replaced by the investigated controller, it is uncertain if the energy usage at the same time will be reduced. This aspect is of course dependent on the conditions provided by the controller that is replaced, but to offer a hint, the benchmark parts of the experiments were repeated with the boundaries of the temperature comfort region as setpoints. In turn, the average room air temperature during the working day became approximately the same when the two controllers were implemented. The prior energy savings of $12-19 \%$ was then reduced to between 8 and $17 \%$. At the same time, the maximum comfort region deviation associated to the benchmark increased to about $-0.5{ }^{\circ} \mathrm{C}$ below +1.5 above during occupied periods, which is equivalent to a major loss of comfort according to the considered metric.

\section{Summary}


This work evaluated an anticipating controller for indoor climate control in office environments that was based on the same principle as model-based controllers but had gone through an extensive complexity reducing process. The investigation was performed through experiments by re-creating a working day in a test facility, and two spaces, representing a meeting and an office room, as well as two weather seasons were considered. The investigated controller was compared to a common feed-back as benchmark, and both controllers were constrained to achieve similar indoor climate quality with respect to deviations from a fixed room air temperature comfort region. From the investigation, it could be concluded that the possibility of reducing energy usage and improving the indoor climate was high: in comparison to the benchmark, the investigated controller resulted in that the total ventilation air supply could be reduced between 12-19\% to maintain a desirable indoor climate during the re-created working day. An additional investigation was also conducted to indicate the influence of comparing the controllers while constraining similar indoor climate qualities. As the potential of energy savings was shown to be closely related to the indoor climate requirements, it could be concluded that the investigated controller either has the possibility of saving energy or improving the indoor climate - depending on the prerequisites for the controller that is replaced. Conclusively, the work showed that it is possible to combine the aspects of implementability and energy efficiency when designing building automation systems for maintaining a desirable indoor climate in office buildings.

\section{Acknowledgement}

Funding of this research has been provided by the department of Energy \& Environment, Chalmers University of Technology.

\section{References}

[1] Energy Efficiency Requirements in Building Codes - Energy Efficiency Policies for New Buildings, International Energy Agency, 2008.

[2] M. Castilla, J.D. Álvarez, M. Berenguel, F. Rodríguez, J.L. Guzmán, M. Pérez, A comparison of thermal comfort predictive control strategies, Energy and Buildings, 43 (10) (2010) 2737-2746.

[3] F. Oldewurtel, A. Parisio, C.N. Jones, D. Gyalistras, M. Gwerder, V. Stauch, B. Lehmann, M. Morari, Use of model predictive control and weather forecasts for energy efficient building climate control, Energy and Buildings, 45 (2012) 15-27. 

energy efficient building heating system, Applied Energy, 88 (9) (2011) 3079-3087.

[5] S. Prívara, J. Siroký, L. Ferkl, J. Cigler, Model predictive control of a building heating system: The first experience, Energy and Buildings, 43 (3) (2010) 564-572.

[6] B. Paris, J. Eynard, S.p. Grieu, T. Talbert, M. Polit, Heating control schemes for energy management in buildings, Energy and Buildings, 42 (10) (2010) 1908-1917.

[7] S.R. West, J.K. Ward, J. Wall, Trial results from a model predictive control and optimisation system for commercial building HVAC, Energy and Buildings, 72 (2014) 271-279.

[8] H. Huang, L. Chen, E. Hu, A new model predictive control scheme for energy and cost savings in

[9] H. Huang, L. Chen, E. Hu, A neural network-based multi-zone modelling approach for predictive control system design in commercial buildings, Energy and Buildings, 97 (2015) 86-97. Identification issues, Applied Energy, 135 (2014) 53-62.

471 [11] M. Maasoumy, M. Razmara, M. Shahbakhti, A. Sangiovanni Vincentelli, Handling model uncertainty in 472 model predictive control for energy efficient buildings, Energy and Buildings, 77 (2014) 377-392.

473 [12] C.R. Touretzky, M. Baldea, Nonlinear model reduction and model predictive control of residential buildings with energy recovery, Journal of Process Control, 24 (2014) 723-739.

475 [13] S. Goyal, H.A. Ingley, P. Barooah, Occupancy-based zone-climate control for energy-efficient buildings: 476 Complexity vs. performance, Applied Energy, 106 (2013) 209-221.

477 [14] F. Oldewurtel, D. Sturzenegger, M. Morari, Importance of occupancy information for building climate control, Applied Energy, 101 (2013) 521-532.

479 [15] J.R. Dobbs, B.M. Hencey, Model predictive HVAC control with online occupancy model, Energy and 480 Buildings, 82 (2014) 675-684. 
[16] X. Zhang, G. Schildbach, D. Sturzenegger, M. Morari, Scenario-based MPC for energy-efficient building climate control under weather and occupancy uncertainty, in: 2013 European Control Conference, 2013.

[17] S. Wang, X. Xu, Simplified building model for transient thermal performance estimation using GA-based parameter identification, International Journal of Thermal Sciences, 42 (2006) 419-432.

[18] M. Gruber, A. Trüschel, J.-O. Dalenbäck, Model-based controllers for indoor climate control in office buildings - Complexity and performance evaluation, Energy and Buildings, 68, Part A (2013) 213-222.

[19] M. Gruber, A. Trüschel, J.-O. Dalenbäck, Combining performance and implementability of model-based controllers for indoor climate control in office environments, Building and Environment, 82 (2014) 228-236.

[20] Y. El Fouih, P. Stabat, P. Riviére, P. Hoang, V. Archambault, Adequacy of air-to-air heat recovery ventilation system applied in low energy buildings, Energy and Buildings, 54 (0) (2012) 29-39.

[21] M.-L. Maripuu, Demand controlled ventilation (DCV) in commercial buildings, PhD thesis, Chalmers University of Technology, Building Services Engineering, 2009.

[22] BBR 19, The Swedish National Board of Housing, Building and Planning, 2011.

[23] SS-EN 12464-1, Ljus och belysning - Light and illumination - Illumination of workplaces - Part 1: Indoor workplaces, SIS Förlag AB, Stockholm, Sweden, 2011 (in Swedish).

[24] Belok, Energy requirements for commercial buildings, Göteborg, Sweden, 2011 (in Swedish).

[25] AFS 2009:2, Workplace Design, Swedish Work Environment Authority, Stockholm, Sweden, 2013 (in Swedish).

[26] L. Jagemar, HVAC Systems, in: Achieving the Desired Indoor Climate, Studentlitteratur, Lund, Sweden, 2003.

[27] L. Ekberg, R1, VVS Tekniska Föreningen, Kristianstad, Sweden, 2006 (in Swedish).

[28] ASHRAE 62.1-2007, Ventilation for Acceptable Indoor Air Quality, Atlanta, USA, 2007.

[29] ISO 7730:2005, Ergonomics of the thermal environment - Analytical determination and interpretation of thermal comfort using calculation of the PMV and PPD indices and local thermal comfort criteria, 2005. 
505 [30] ASHRAE 55-2004, Thermal Environmental Conditions for Human Occupancy, in, ASHRAE, Atlanta, 506 USA, 2004.

507 [31] EN-15251, Indoor Environmental Input Parameters for Design and Assessment of Energy Performance of 508 Buildings - Addressing Indoor Air Quality, Thermal Environment, Lighting and Acoustics, CEN, 2007.

509 [32] P.O. Fanger, Thermal Comfort, McGraw Hill Book Company, New York, 1970.

510 [33] T. Hägglund, Praktisk processreglering (Applied process control), Studentlitteratur, Lund, Sweden, 2008 (in 511 Swedish).

512 [34] M. Gruber, Demand-based control of indoor climate in office buildings, Licentiate thesis, Chalmers

513 University of Technology, Building Services Engineering, 2012.

514 [35] C. Blomqvist, M. Sandberg, Air movement through horizontal openings in buildings - A model study, 515 University of Gävle, Centre of Built Environment, 2004. 
Figure

Figure 1

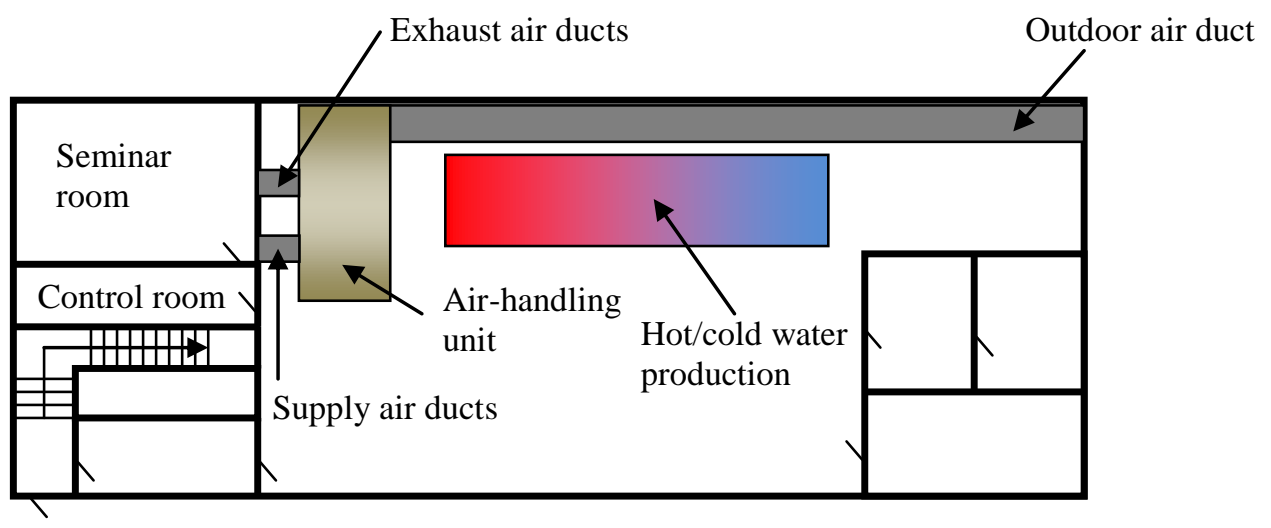


Figure 2

External wall, $6.2 \mathrm{~m}$

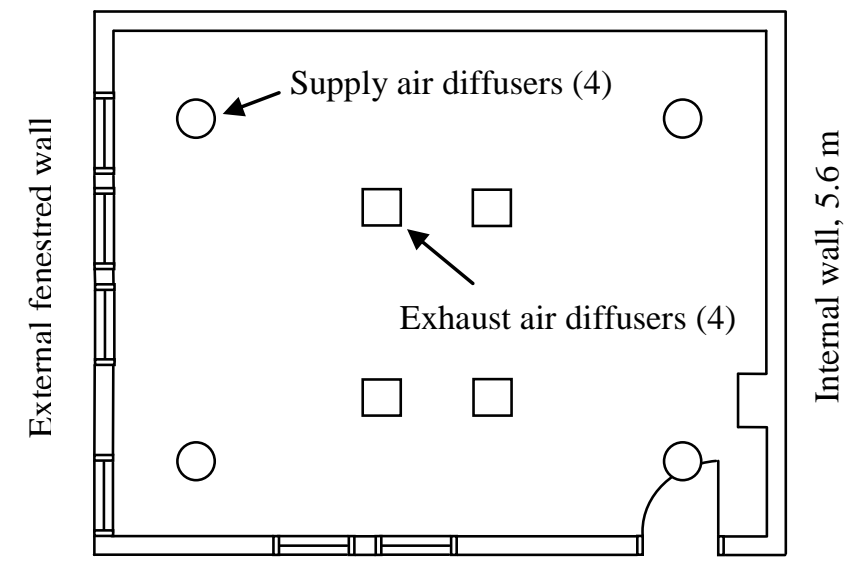

Internal fenestred wall 


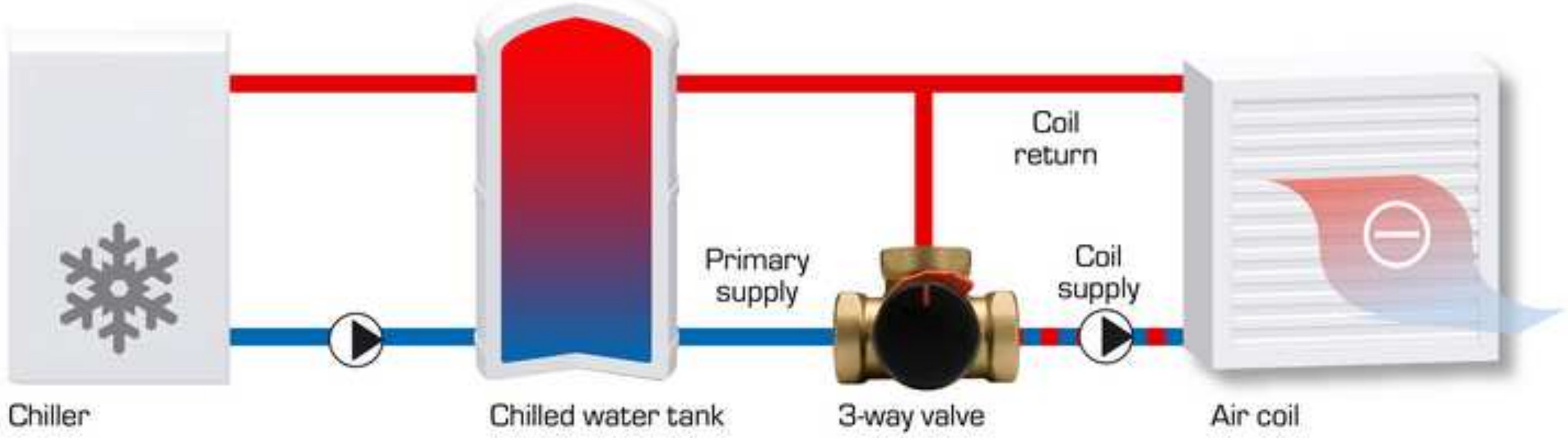


Figure 4
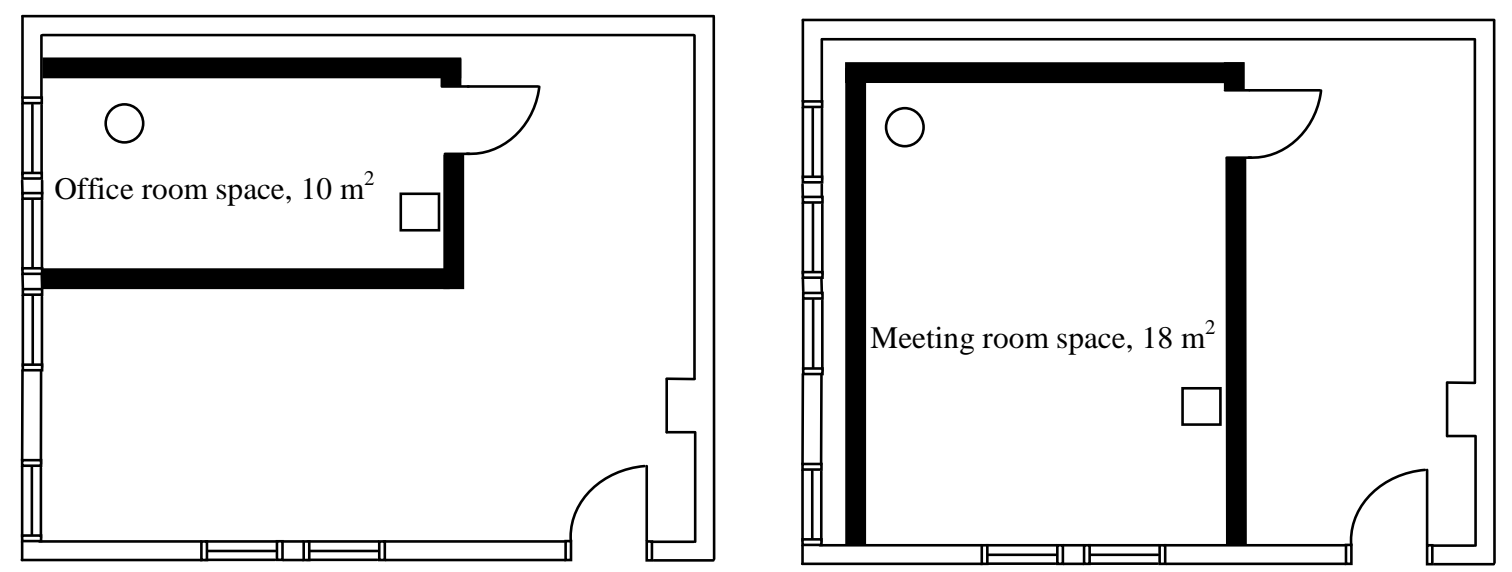


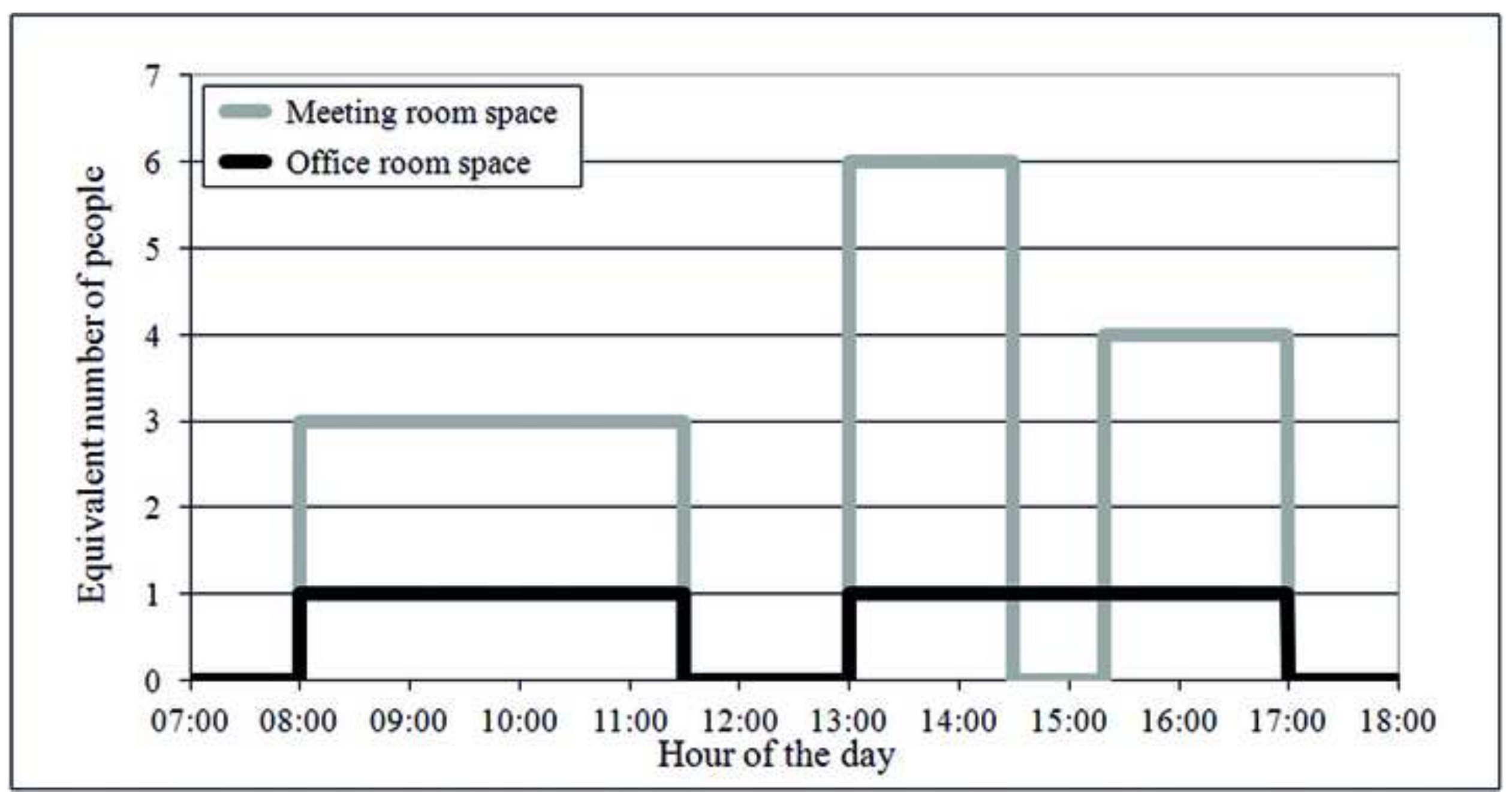


Figure 6
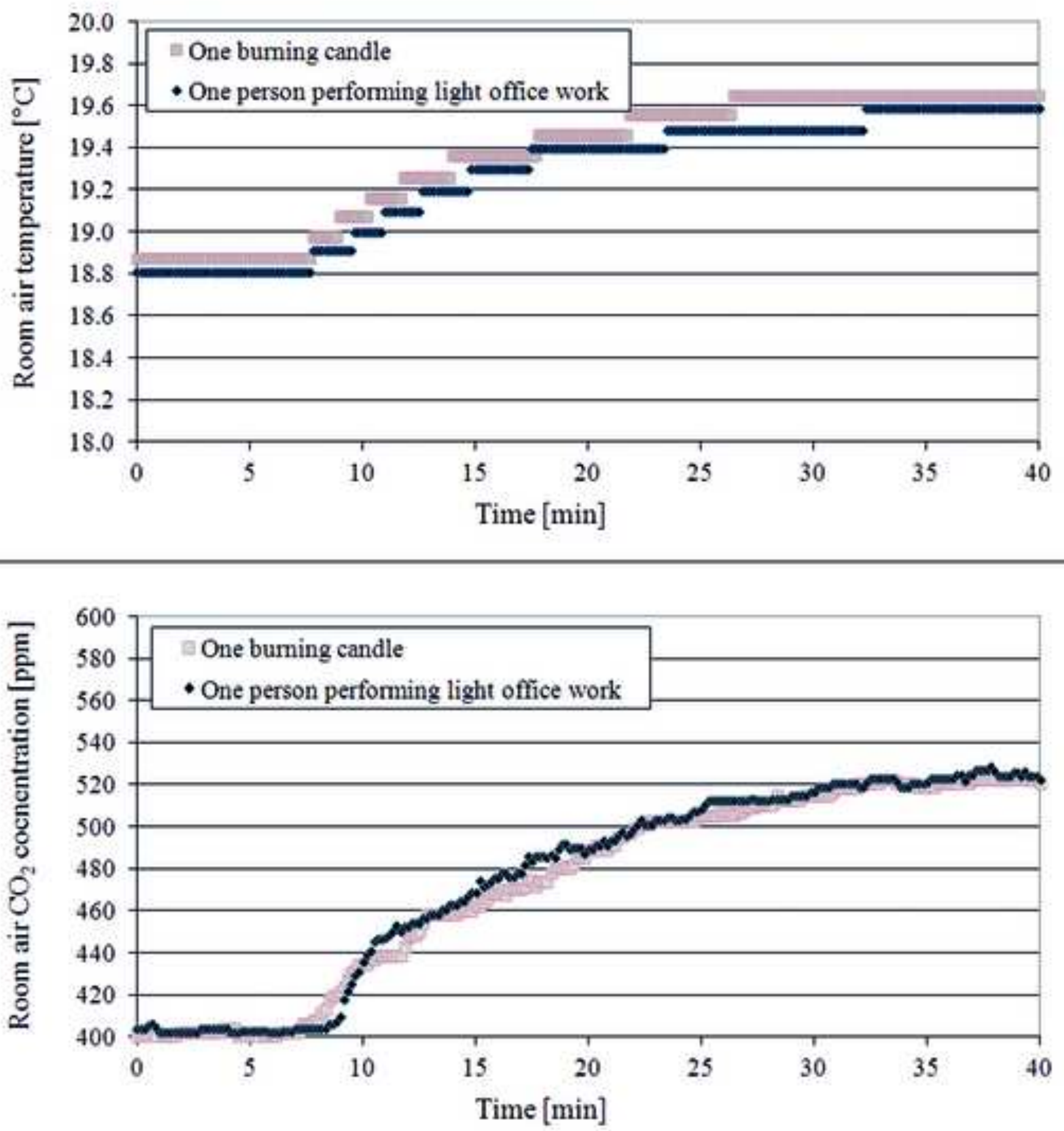
Figure 7

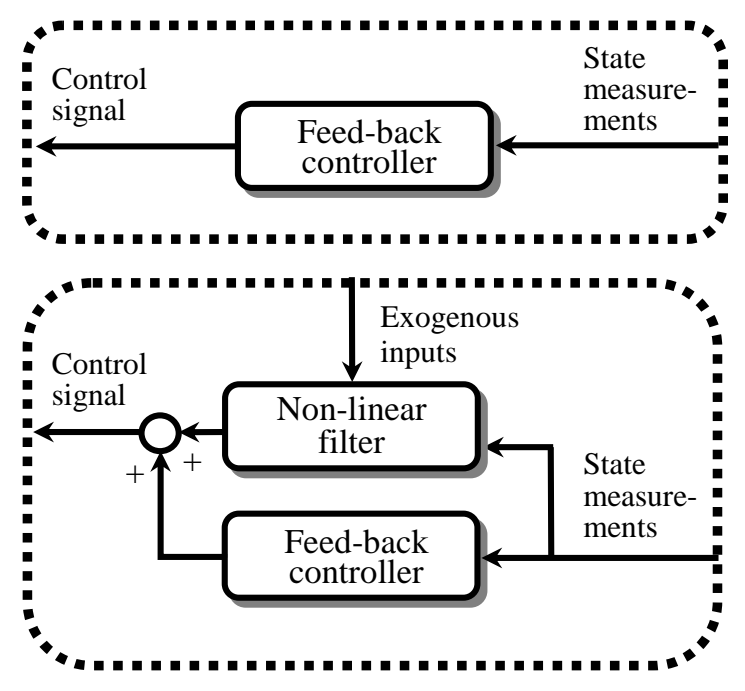


Figure 8

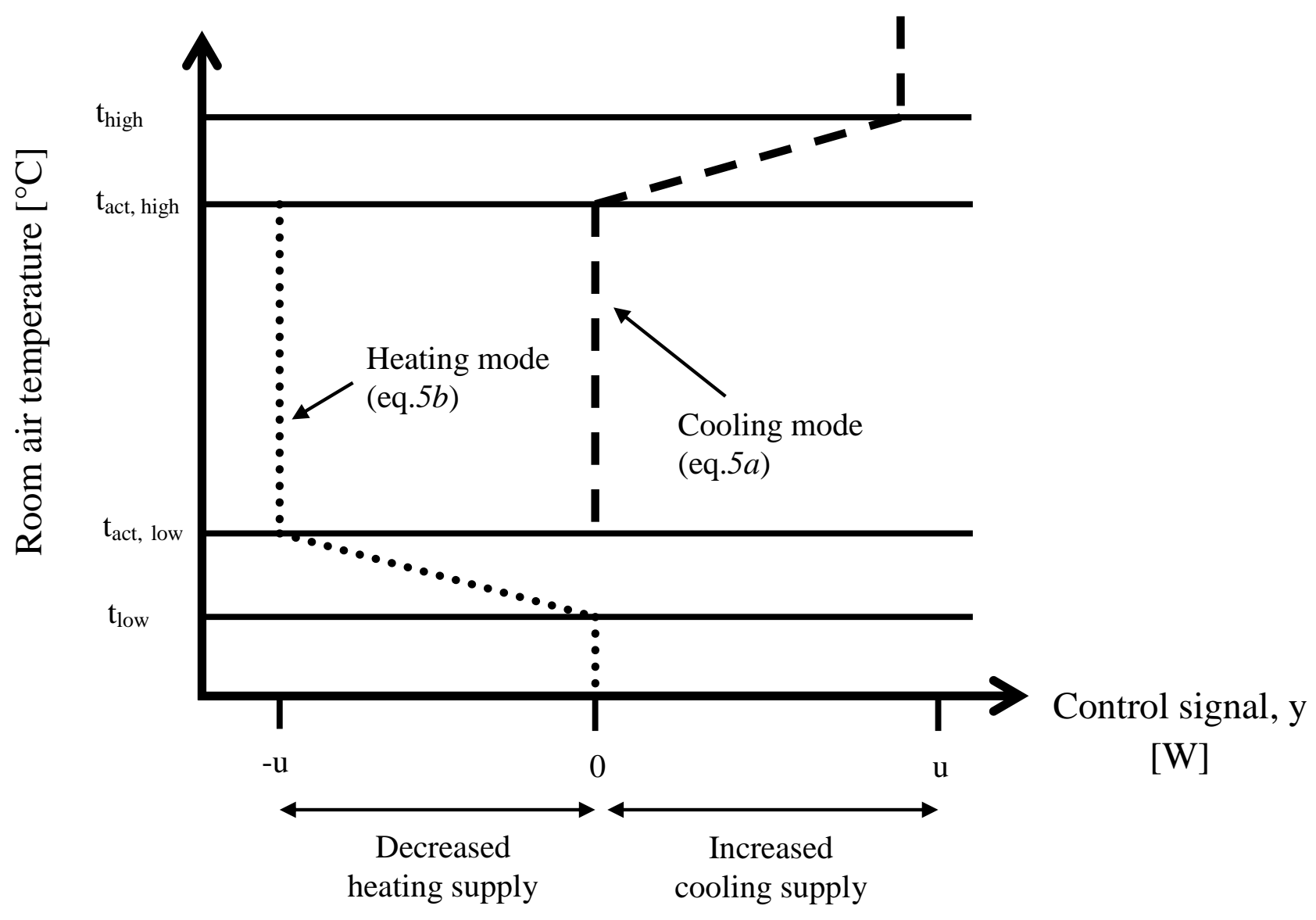




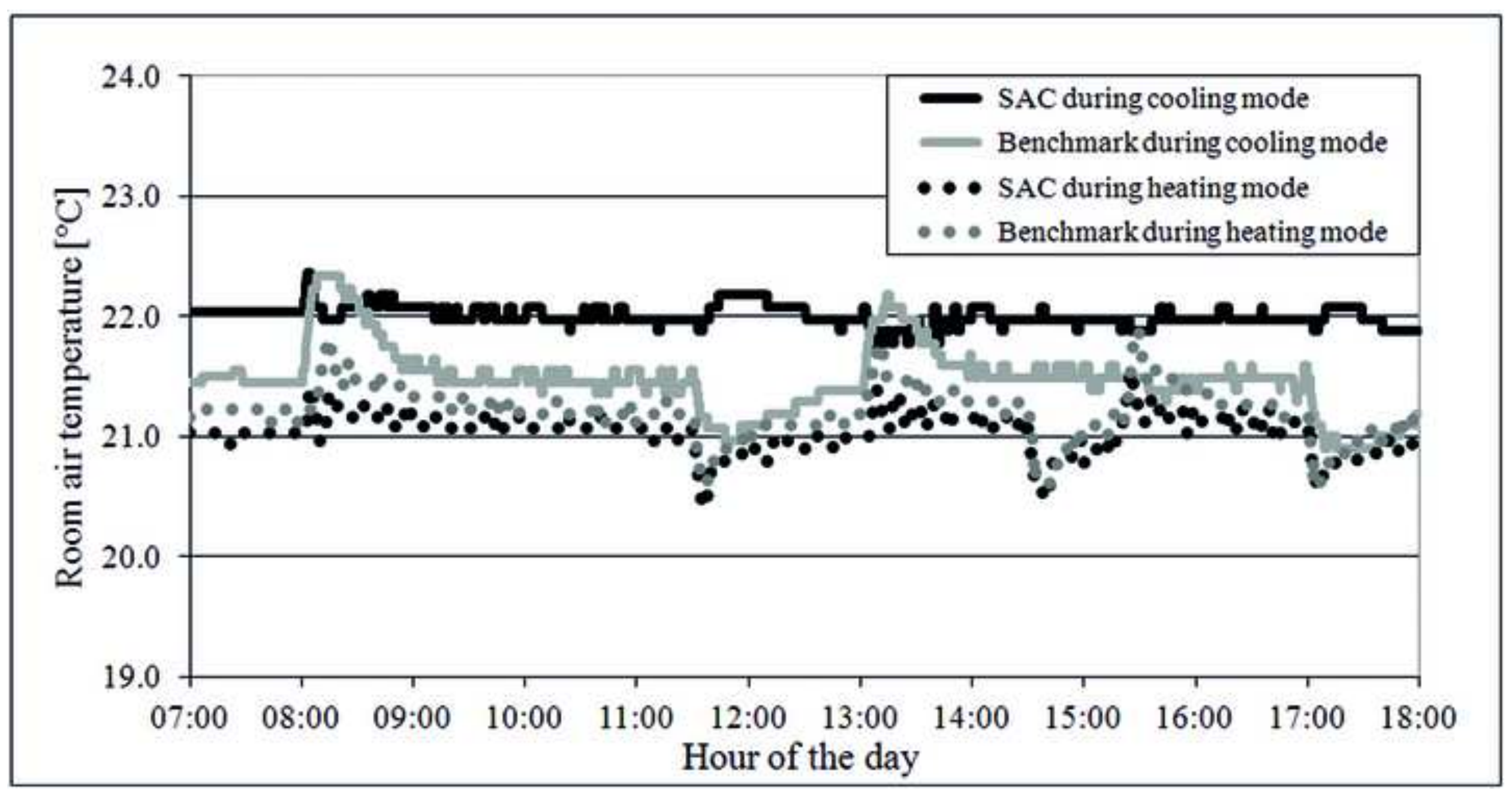




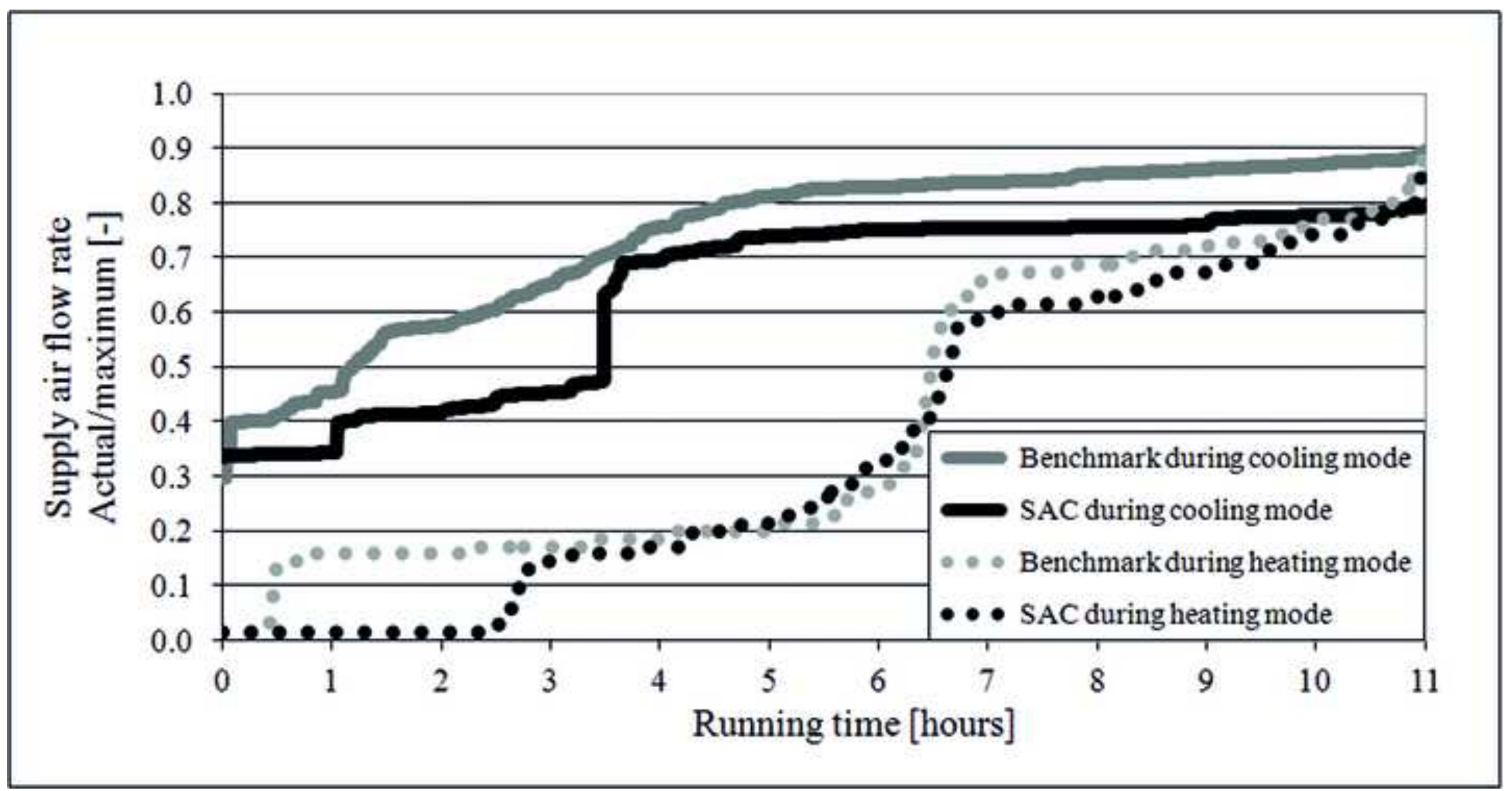




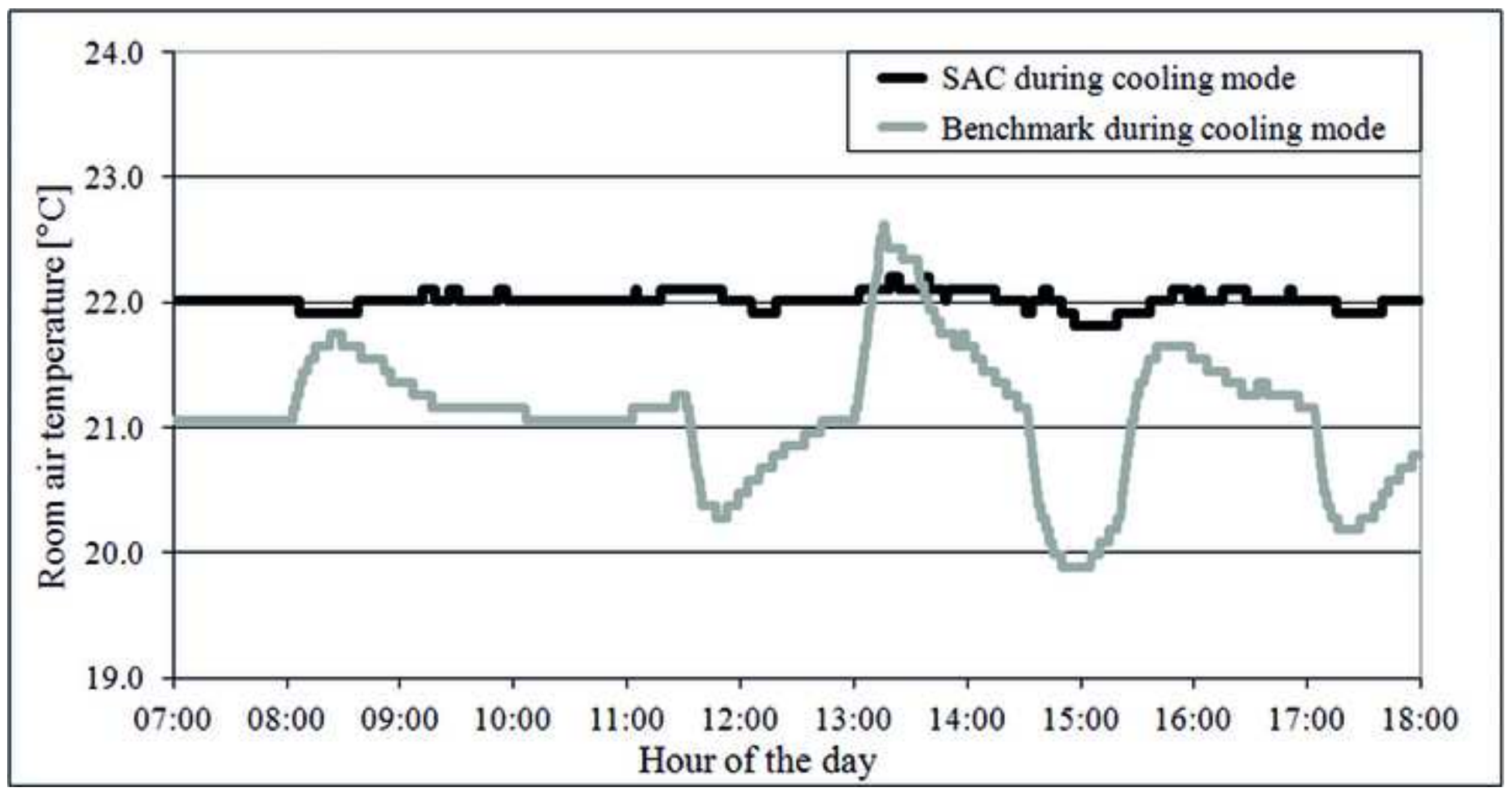




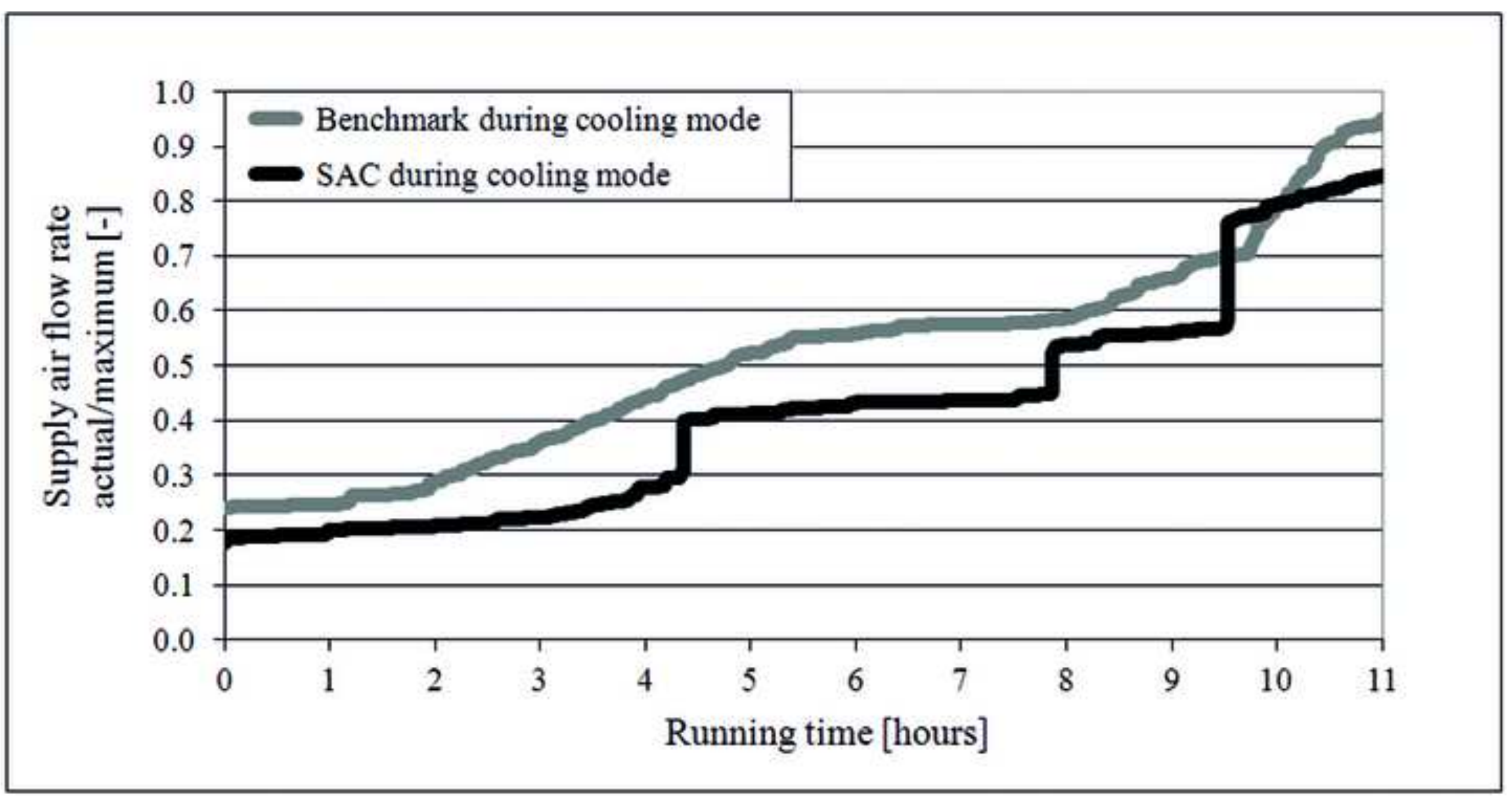


Table 1. Summary of HVAC components involved during the experiments. OA (Outdoor Air)

\begin{tabular}{lll}
\hline First level (Production units) & Purpose & Control strategy \\
Electrical boiler & Hot water production & On/off \\
Combined heat pump and chiller (2) & Simultaneous production of hot and cold water & On/off \\
Ground source heat pump & Cold water production & Variable bore-hole flow rate \\
Dry cooler (2) & Heat exchange between water and OA & Variable flow on OA-side \\
Hot and cold water tanks (5) & Storage of heating and cooling carriers & - \\
\hline Distribution system $\mathbf{1}^{\text {st }} \leftrightarrow \mathbf{2}^{\text {nd }}$ levels & Purpose & Control strategy \\
Pipings of three temperature levels & Transportation of carriers & - \\
Circulation pumps (3) & Pressure control & Variable speed drive \\
\hline Second level (Air handling unit) & Purpose & Control strategy \\
Hot water connected air coil & Heating of OA & Variable water inlet temp. \\
Cold water connected air coil & Cooling / dehumidifying of OA & Variable water inlet temp. \\
Circulation pumps (2) & Pressure control at coil inlets & Variable speed drive \\
Supply air fan & Track control signal to the supply air diffusers & Variable speed drive \\
Exhaust air fan & Track flow on the supply air side & Variable speed drive \\
\hline Distribution system $\mathbf{2}^{\text {nd }} \leftrightarrow \mathbf{3}^{\text {rd }}$ levels & Purpose & Control strategy \\
Four ducts in each direction & Transportation of ventilation air & - \\
\hline Third level (Seminar room) & Purpose & Control strategy \\
Supply air diffusers (4) & Actuator for room air temperature & Automated opening \\
Exhaust air diffusers $(4)$ & Extraction of room air for balanced ventilation & Manual balancing dampers \\
\hline
\end{tabular}


Table 2. Evaluated scenarios. (SAC=Simplified Anticipating Controller)

\begin{tabular}{l|lll}
\hline Controller & Ambient climate & Space & HVAC system mode \\
\hline SAC & Winter & Office room & Heating \\
Benchmark & Winter & Office room & Heating \\
SAC & Summer & Office room & Cooling \\
Benchmark & Summer & Office room & Cooling \\
SAC & Irrelevant & Meeting room & Cooling \\
Benchmark & Irrelevant & Meeting room & Cooling \\
\hline
\end{tabular}


Table 3. Indicated energy savings associated to the investigated controller when compared to the benchmark for the considered scenarios.

\begin{tabular}{cc|c}
\hline \multicolumn{2}{c|}{ Scenario } & Total ventilation flow savings [\%] \\
\hline \multirow{2}{*}{ Office Room } & - Summer & 14 \\
& - Winter & 12 \\
Meeting room & & 19 \\
\hline
\end{tabular}

